\title{
Espiritualidade/religiosidade no processo saúde-doença dos pacientes com Doença Falciforme
}

\author{
Spirituality/religiosity in the health-disease process of patients with Sickle Cell Disease
}

Espiritualidad/religiosidad en el proceso salud-enfermedad de pacientes con Enfermedad de Células Falciforme

Augusto Cézar Apolinário dos Santos ${ }^{1 *}$, Rodrigo De Martin Almeida ${ }^{2}$, Olivia Franco dos Santos ${ }^{3}$, Renato Lourenço de Medeiros ${ }^{2}$, Jéssica Diniz Rezende ${ }^{1}$, Jordana Alícia Silveira Lopes ${ }^{3}$, Tássia Mariana Moreira Paz ${ }^{1}$, Thais Sette Espósito ${ }^{1}$, Daniela de Oliveira Werneck Rodrigues ${ }^{4}$.

\section{RESUMO}

Objetivo: Realizar uma revisão sistemática da literatura sobre o impacto que a espiritualidade/religiosidade (E/R) exerce no processo saúde-doença dos indivíduos portadores de Doença Falciforme (DF) e despertar nos profissionais de saúde a possibilidade do uso de medidas alternativas complementares (MACs) associadas ao tratamento convencional, em especial o uso da E/R na DF. Métodos: Foi realizada uma pesquisa com os descritores "spirituality", "religion" e "sickle cell disease" nas bases de dados eletrônicas SciELO, BIREME, Medline, PubMed e Lilacs no período de 10 a 18 de maio de 2020. Critérios de inclusão: artigos que relacionaram de forma direta ou indireta a $E / R$ aos pacientes com DF. Critérios de exclusão: artigos não pertinentes à relação E/R e DF. Foram selecionados 27 artigos científicos. Resultados: Foi verificado o uso de MACs no manejo dos pacientes com DF com um melhor enfrentamento da doença. A E/R tem alta frequência de utilização e apresentou resultados significativos na qualidade de vida desta população. Considerações finais: $O$ uso da E/R faz parte da atenção integral ao paciente com DF e deve ser acrescido no manejo terapêutico convencional. Os profissionais de saúde encontram dificuldades na abordagem e associação da $E / R$ ao tratamento e sugere-se sua capacitação nesta área.

Palavras-chave: Doença Falciforme, Espiritualidade, Religião, Qualidade de vida.

\section{ABSTRACT}

Objective: To conduct a systematic review of the literature on the impact of spirituality/religiosity $(\mathrm{S} / \mathrm{R})$ on the health-disease process of individuals with sickle cell disease (SCD) and acquaint health professionals with the possibility of using complementary and alternative measures (CAM) in association with conventional treatment, especially the use of S/R in SCD. Methods: SciELO, BIREME, Medline, PubMed and Lilacs electronic databases were searched for articles published between 10 and 18 May 2020 that include the descriptors "spirituality", "religion" and "sickle cell disease". Inclusion criteria: articles that established any correlation between S/R and patients with SCD. Exclusion criteria: articles not relevant to the S/R and SCD correlation. Twenty-seven scientific articles were selected. Results: We were able to verify that the use of CAM in the management of patients with SCD is associated with better coping. S/R is a widely used resource and it has shown significant results in the quality of life of this population. Final considerations: The use of $S / R$ is part of the comprehensive care for patients with SCD and should be associated with conventional therapeutic management. Health professionals commonly find difficult to approach and associate S/R with patient treatment. Therefore, training on this matter would be indicated.

Key words: Sickle cell disease, Spirituality, Religion, Quality of life.

${ }^{1}$ Centro Universitário Presidente Antônio Carlos (UNIPAC-JF), Juiz de Fora - MG.

*E-mail: augustoapolinario@gmail.com

${ }^{2}$ Faculdade de Ciências Médicas e da Saúde de Juiz de Fora (SUPREMA), Juiz de Fora - MG.

3Universidade Federal de Juiz de Fora (UFJF), Juiz de Fora - MG.

${ }^{4}$ Fundação Hemominas (Hemominas), Juiz de Fora - MG. 


\section{RESUMEN}

Objetivo: Llevar a cabo una revisión sistemática de la literatura sobre el impacto que la espiritualidad/religiosidad (E/R) tiene en el proceso de salud-enfermedad de las personas con enfermedad de células falciformes (ECF) y despertar en los profesionales de la salud la posibilidad de utilizar medidas alternativas complementarias (MACs) asociado con el tratamiento convencional. Métodos: Se realizó una búsqueda con los descriptores "spirituality", "religion" y "sickle cell disease" en las bases de datos electrónicas SciELO, BIREME, Medline, PubMed y Lilacs en el período del 10 al 18 de mayo de 2020. Criterios de inclusión: artículos quienes relacionaron E/R a pacientes con ECF. Criterios de exclusión: artículos no relevantes para la relación E/R y ECF. Se seleccionaron 27 artículos. Resultados: El uso de MAC se verifico en el tratamiento de pacientes con DF con mejor afrontamiento de la enfermedad. E/R tiene una alta frecuencia de uso y ha mostrado resultados significativos en la calidad de vida. Consideraciones finales: El uso de E/R es parte de la atención integral para pacientes con ECF y debe agregarse al tratamiento terapéutico convencional. Los profesionales de la salud encuentran difícil abordar y asociar E/R con el tratamiento y se sugere su capacitacion en esta área.

Palabras clave: Anemia de células falciformes, Espiritualidad, Religión, Calidad de vida.

\section{INTRODUÇÃO}

Doença Falciforme (DF) é uma hemoglobinopatia hereditária autossômica recessiva com mutação no alelo beta-S da globina (COOPER-EFFA M, et al., 2001). A condição se caracteriza pela transformação morfológica da hemoglobina em decorrência da substituição do ácido glutâmico pela valina na sexta posição da cadeia beta-globina no cromossomo 11. A partir da descrição de sua base molecular foram identificadas alterações inflamatórias na fisiopatogenia. Diante de situações em que o portador de DF é submetido a hipóxia, desidratação e acidose, ocorre polimerização da hemoglobina S e lesão endotelial. Desse modo, deflagramse fenômenos vaso-oclusivos desencadeando a sintomatologia (TAYLOR LEV, et al., 2011).

A DF é uma enfermidade crônica que pode evoluir com sintomas leves e de maior gravidade (CLAYTONJONES D, et al., 2016). Manifestações como crises álgicas agudas, anemia e danos crônicos a alguns órgãos estão presentes na maioria dos pacientes, assim como os quadros infecciosos e úlceras de perna possuem alta prevalência (AHMED S, et al., 2006; TAYLOR LEV, et al., 2011; UMEH NI, et al., 2017). Nos quadros mais graves podem ocorrer acidente vascular cerebral, síndrome torácica aguda, septicemia pneumocócica, sequestro esplênico, insuficiência renal e morte (COOPER-EFFA M, et al., 2001).

A DF é originária da Ásia Menor e da África, sendo que a dispersão do gene siclêmico ocorreu com a imigração forçada de africanos para o trabalho escravo e expandiu com o processo de miscigenação dos povos (PEREIRA SAS, et al., 2008; TAYLOR LEV, et al., 2011). Estima-se, atualmente, que a DF acometa cerca de $7 \%$ da população mundial, com mais de 300 mil nascimentos ao ano de bebês portadores da alteração gênica. E com distribuição de forma heterogênea nos territórios, com elevada incidência onde a proporção populacional negra é maior (TONI-UEBARI TK, INUSA BPD, 2009; PEREIRA SAS, et al., 2008). Dada a relevância epidemiológica, a DF é considerada a doença hereditária monogênica mais prevalente do mundo (AHMED S, et al., 2006)

Estudar a DF de forma ampla, somando conhecimentos de medidas alternativas complementares (MACs), é de extrema importância, uma vez demonstrado o alto impacto na qualidade de vida (QV) que os pacientes apresentam diante da condição crônica (ADZIKA VA, et al., 2017). A fisiopatogenia da DF culmina em danos teciduais que promovem a liberação de mediadores inflamatórios de forma sistêmica, levando à ativação de nociceptores periféricos e desencadeando crises álgicas recorrentes (TAYLOR LEV, et al., 2011). Tais crises causam comprometimento em diversas áreas da vida do paciente (ADEGBOLA M, 2011).

Nesse sentido, a dor crônica pode ser compreendida de modo multifatorial, ou seja, resultante de aspectos biológicos, psicológicos, sociológicos e espirituais (TAYLOR LEV, et al., 2011). Assim, as MACs - terapias baseadas em intervenções mente-corpo, terapias baseadas no corpo e terapias de base biológica e manipulados - possibilitam uma abordagem integral com foco na melhora da QV do paciente e devem ser exploradas de maneira multidimensional (MAJUMDAR S, et al., 2013). 
A espiritualidade/religiosidade $(E / R)$ faz parte do cotidiano de alta parcela populacional e exerce papel importante em variadas situações inerentes à vida do indivíduo (GOMES NS, et al., 2014). Os pacientes com DF experimentam situações que os impulsionam a buscar apoio na $E / R$ para o enfrentamento de seus dilemas, como o medo da morte, a percepção de uma vida sem esperança, a busca em lidar melhor com a doença - bem como o processo de aceitação desta -, a depressão, a baixo autoestima e outros (ADEGBOLA $M, 2011)$. Tal fato corrobora para a importância da atenção ao aspecto espiritual no paciente falciforme pois o uso da E/R configura-se como uma das principais MACs praticadas pelos pacientes com DF (YOON SL e BLACK S, 2006; CLAYTON-JONES D, et al., 2016).

A priori, para melhor entendimento a respeito da temática de MACs na DF, em especial o uso da $E / R$, torna-se necessário analisar os conceitos de espiritualidade, religião e religiosidade. Embora existam controvérsias sobre o conceito de espiritualidade na literatura científica, este termo pode ser compreendido como algo inerente a todo ser humano, uma vez que todos buscam significar e encontrar respostas à sua vivência (GOMES NS, et al., 2014; TAYLOR LEV, et al., 2011). A espiritualidade se pauta na busca de experiências com o transcendente, configurando uma condição que possibilita ao indivíduo ultrapassar o seu universo e colocar-se frente às questões que emergem de sua interioridade na tentativa de responder aos questionamentos existenciais (GOMES NS, et al., 2014; COOPER-EFFA M, et al., 2001).

A religião, por sua vez, é entendida como uma das formas pelas quais os indivíduos buscam alcançar o transcendente, ou seja, as crenças e ritos se estruturam de forma hierarquizada e servem de instrumento para o contato com o transcendente (GOMES NS, et al., 2014; DENNIS-ANTIWI JA, et al., 2018). Já a religiosidade é a vivência da religião e o impacto desta na vida do indivíduo manifesta-se como expressão da espiritualidade alcançada (GOMES NS, et al., 2014; COOPER-EFFA M, et al., 2001). Ademais, sabe-se que a E/R pode imprimir tanto coping positivo, quanto coping negativo, que podem ou não auxiliar no bem-estar biopsicossocial (GOMES MV, et al., 2019).

Pacientes com DF que fazem uso da $E / R$ relatam relações fortes e positivas entre sua $Q V$ e espiritualidade, uma vez que tal combinação reflete um equilíbrio holístico do paciente em suas dimensões biofísica, psicológica, sociocultural e espiritual (ADEGBOLA M, 2011; BAVERSTOCK A e FINLAY F, 2011; YOON SL e BLACK S, 2006; CRONIN RM, et al., 2018;). Nesse ínterim, a Psicoimunologia reconhece no uso da E/R a modulação psicológica e responsividade ideal aos agentes estressores que atuam no curso das condições crônicas (CLAYTON-JONES D, et al., 2016). Isso explica-se através da otimização das vias psiconeuroimunológicas com redução na liberação de células imunes - envolvidas no estresse - associado a um aumento na quantidade de neurotransmissores envolvidos no controle da dor (GOMES MV, et al., 2019).

O objetivo desta revisão é identificar artigos publicados que relacionam a $E / R$ à $D F$ para compreender os impactos da religiosidade no processo saúde-doença e buscar uma visão integral pelos profissionais de saúde acerca da DF, despertando a possibilidade do uso de MACs associadas ao tratamento convencional dessa patologia.

\section{MÉTODOS}

O presente estudo trata-se de uma revisão sistemática da literatura, no qual foram avaliados artigos publicados em revistas científicas nacionais e internacionais. Foram escolhidos como descritores para a busca os termos "spirituality", "religion" e "sickle cell disease", ambos escolhidos mediante consulta no Medical Subject Headings (MesH) e no Descritores em Ciência da Saúde (DeCS). As pesquisas foram realizadas nas bases de dados eletrônicas SciELO, BIREME, Medline, PubMed e Lilacs no período entre 10 e 18 de maio de 2020.

Em cada base de dados supracitadas foram realizadas duas buscas: inicialmente relacionou-se os descritores "spirituality" e "sickle cell disease" e, em seguida, os descritores "religion" e "sickle cell disease". Foram encontrados 243 resultados, dos quais 146 eram arquivos duplicados, resultando, então, 97 artigos. Os resumos destes foram separados de forma independente e analisados por dois pesquisadores que excluíram aqueles que não correlacionavam a $E / R$ à $Q V$ dos pacientes com DF. Dos 97 artigos, 70 foram excluídos por não atenderem aos objetivos da pesquisa, restando 27. 
Ao término da escolha dos 27 artigos, os pesquisadores se reuniram para discutir os critérios de inclusão e exclusão empregados na elegibilidade dos artigos. Diante da escassez de trabalhos com foco na E/R do paciente com DF, não foi empregado corte temporal, reafirmaram como critérios de inclusão todos os estudos que relacionaram de forma direta ou indireta o fator $E / R$ aos pacientes portadores de $D F$ e como critérios de exclusão os artigos não pertinentes à relação $E / R$ e $D F$.

Ao final do debate sobre os critérios de elegibilidade, mantiveram-se os 27 artigos. Em seguida, esses foram lidos e confrontados para a escrita da presente revisão bibliográfica. O processo de seleção dos artigos encontra-se esquematizado abaixo (Figura 1).

Figura 1 - Processo de seleção dos artigos científicos

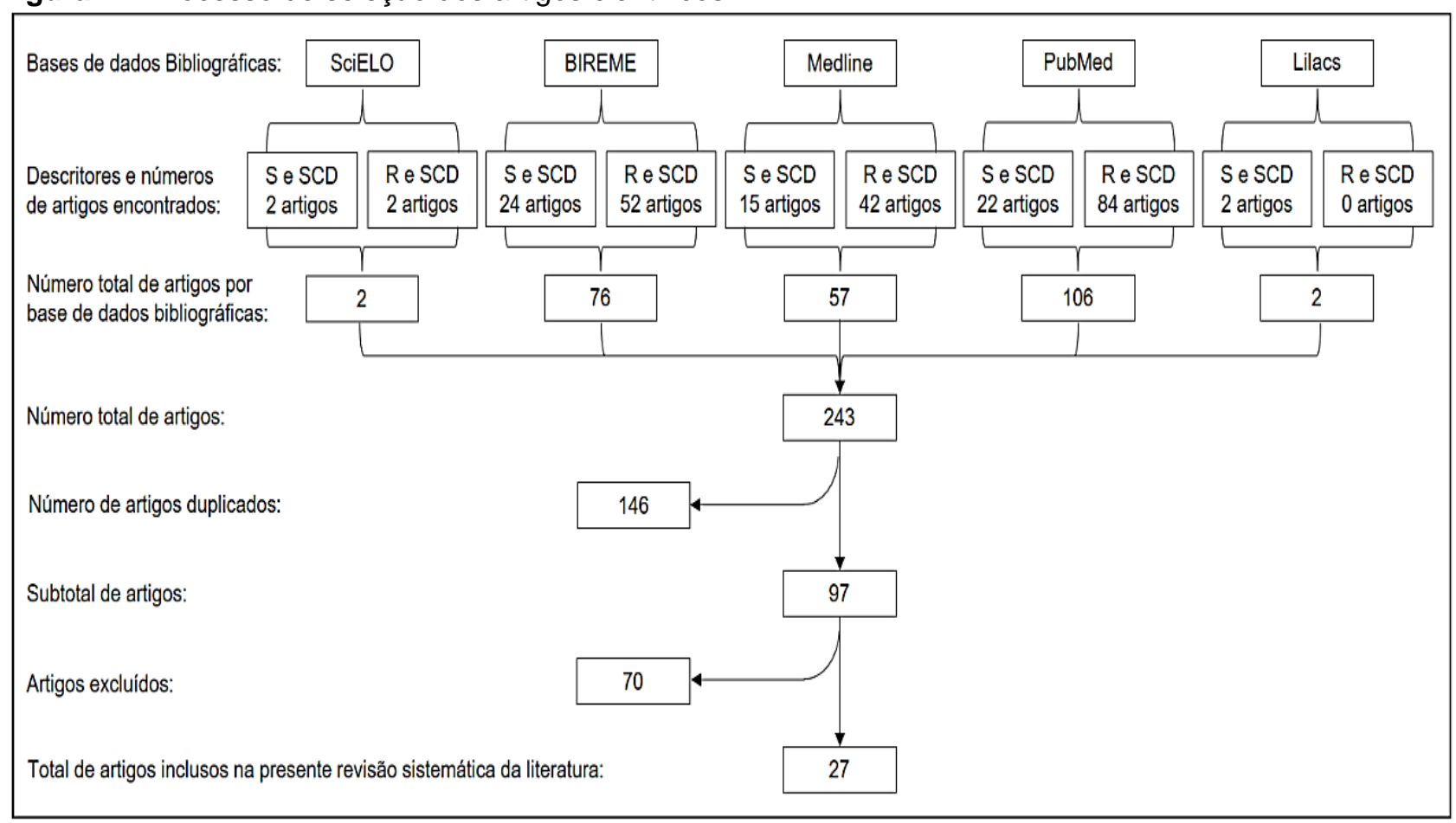

S e SCD: Descritores "Spirituality" e "Sickle Cell Disease"; R e SCD: Descritores "Religion" e "Sickle Cell Disease"

Fonte: Santos ACA, et al., 2020.

\section{RESULTADOS E DISCUSSÃO}

Os artigos consultados trazem informações acerca de pontos fundamentais sobre a relação entre a E/R e a DF, que vão desde características subjetivas, transpondo aspectos psicológicos, até objetivas, como a possibilidade de mensurar a diminuição da dor na DF por meio de MACs. Desse modo, destacamos, a seguir, as informações mais relevantes dos estudos analisados e discutimos esses dados, relacionando-os, visando à melhor compreensão do cenário em estudo.

O perfil religioso/espiritual (R/E) dos pacientes com DF é notório. Cronin RM, et al. (2018), Adegbola M (2011) e Dennis-Antiwi JA, et al. (2018) relataram que a população afro-americana, principal perfil de pacientes com DF, possui historicamente um nível elevado de espiritualidade. Taylor LEV, et al. (2013) observaram que $70 \%$ dos pacientes consideram a espiritualidade uma parte importante de suas vidas e quase $50 \%$ realizam atividades espirituais/religiosas. Já na população de estudo de Clayton-Jones D, et al. (2016), $100 \%$ dos adolescentes baseiam-se em sua espiritualidade para lidar com os desafios da DF e $88,8 \%$ afirmam possuir crenças religiosas.

Na pesquisa de Cronin RM, et al. (2018), 76\% dos pacientes se classificaram como "bastante" ou "muito" R/E. Nos entrevistados de Cotton S, et al. (2009), 100\% possuem crença em Deus ou em um poder superior e $59 \%$ se consideram muito ou moderadamente R/E. Yoon SL e Black S (2006), demonstraram que 72,5\% dos pacientes fazem uso da oração para controle da dor e aproximadamente $55 \%$ buscam a cura espiritual por outros meios além da oração. 
Com relação à frequência e as práticas de espiritualidade, Gomes MV, et al. (2019) demonstraram que $51,8 \%$ dos pacientes com DF frequentam cultos religiosos pelo menos uma vez por semana, 33,6\% frequentam uma a seis vezes ao mês e $59,1 \%$ fazem uso da religiosidade diariamente. Já na pesquisa de Cotton S, et al. (2009), 64\% participam de práticas religiosas pelo menos uma vez por semana, 50\% pertencem a uma igreja, $37 \%$ relatam orar uma vez ou mais por dia, $26 \%$ oram uma vez na semana e $37 \%$ fazem uso da oração mais de uma vez para gerir melhor seus sintomas.

Taylor LEV, et al. (2013) detectaram que quase 50\% dos entrevistados realizam atividades R/E pelo menos uma vez ao dia. Para Adegbola M (2011), frequentar igrejas uma vez ou mais por semana associa-se a menos dor. Esse dado corrobora com Clayton-Jones D e Haglund K, 2015 que relataram que práticas espirituais e religiosas, como a frequência moderada de oração, são associadas com pontuações mais baixas para intensidade da dor em adultos. Foi observado que a prática da oração ocorria mais frequentemente durante as crises álgica e que indivíduos em piores condições de saúde são mais propensos a contar com a religião em sua vivência (CLAYTON-JONES D, et al., 2016; BEDIAKO SM, et al., 2011).

A espiritualidade e estratégias de enfrentamento religioso são aspectos importantes no controle da dor crônica (COOPER-EFFA M, et al., 2001; ADEGBOLA M, 2011; TAYLOR LEV, et al., 2013). Dentre as práticas espirituais, a oração foi uma das ações mais encontradas nos artigos que embasam este estudo e, segundo os pacientes, ela traz melhora em diversos aspectos, como sentimento de esperança, alívio da dor e ansiedade (FOSTER N e ELLIS M, 2018; CLAYTON-JONES D, et al., 2016; BEDIAKO SM, et al., 2011; ADEGBOLA M, 2011; HARRISON MO, et al., 2005).

Segundo Harrison MO, et al. (2005), o estudo da Bíblia e a religiosidade intrínseca não foram significativamente relacionados à dor, mas a presença na igreja pode ser vista como uma variável rica, com influências no enfrentamento ativo, na reformulação cognitiva e no apoio social, o que traz benefícios em vários campos da vida. Cotton S, et al. (2012), observaram o uso predominante de enfrentamento religioso, principalmente a oração, para lidar com a natureza imprevisível e dolorosa da doença e que a religiosidade é demonstrada através da conexão com Deus por meio de oração, leitura das escrituras, participação de serviços e tradições religiosas.

Frente ao uso de MACs em pacientes com DF com crises álgicas, Yoon SL e Black S (2006) evidenciaram a oração como a mais prevalente, presente em $72,5 \%$ dos casos, seguida pela cura espiritual por outros em aproximadamente $55 \%$, massagem terapêutica em $50 \%$, técnicas de relaxamento em $37 \%$, ingesta de megavitaminas em $30,6 \%$ e uso de produtos fitoterápicos em $17,7 \%$. Quando questionados sobre o interesse de utilizar algum tipo de MAC, mostraram interesse na oração $(95,2 \%)$, massagem terapêutica $(79,4 \%)$, técnica de relaxamento $(73 \%)$, cura espiritual por outros $(71 \%)$, acupuntura $(11,3 \%)$ e hipnose $(12,7 \%)$. Cotton $S$, et al. (2012) encontraram que para os adolescentes, a arte, o canto, a música, a dança, a atuação, a leitura e a escrita foram relacionadas a um nível de conexão que lhes permitem transcender seus problemas de saúde e sentirem alívio dos fatores estressores.

De acordo com a Organização Mundial de Saúde (OMS), a qualidade de vida (QV) é a percepção do indivíduo sobre sua posição na vida, no contexto global em que vive e em relação a seus objetivos, expectativas e preocupações. Segundo Harrison MO, et al. (2005), E/R tem sido identificada por indivíduos com DF como fator importante para minimizar o estresse e melhorar a QV. Seu estudo demonstrou associações positivas entre $E / R$ e melhores resultados de saúde física e mental.

$\mathrm{Na}$ pesquisa de Pereira SAS, et al. (2008), apenas 24\% dos pacientes com DF encontravam-se trabalhando e, dos que não trabalhavam, $72 \%$ apontaram a doença como a principal causa de impedimento para o trabalho, revelando impacto negativo da doença no cotidiano. Ademais, Cronin RM, et al. (2018) abordaram o absenteísmo a consultas médicas por pacientes com DF e observaram que $87 \%$ dos adultos e $65 \%$ das crianças já perderam consulta por diversas causas, sendo notado que quanto menor o grau de espiritualidade, maior o número de falta às consultas. Segundo Cotton $S$, et al. (2012), as crianças com DF apresentam frequentemente interrupções nas atividades diárias, como a escola, além de maior propensão a sintomas de ansiedade. 
Com relação aos efeitos negativos da E/R nos pacientes com DF, entre os entrevistados de Cotton $S$, et al. (2009), 31\% inferiram que a doença aconteceu por obra maligna e 36\% relataram questionar o amor de Deus. Gomes MV, et al. (2019) perceberam que o sofrimento espiritual, a incompreensão de seu estado de saúde, o pensamento de castigo divino, a percepção de contraditoriedade em sua crença e o sentimento de abandono se fizeram presentes. Para Foster N e Ellis M (2018), a espiritualidade é considerada uma fonte de apoio, especialmente durante as crises álgicas. Apesar de alguns pacientes acreditarem que sua condição era um teste de Deus ou uma punição, outros consideravam a oração como estratégia de enfrentamento.

Os portadores de doenças crônicas são três a quatro vezes mais propensos a desenvolver distúrbios de saúde mental. Pacientes com DF apresentam risco de problemas em diversas áreas funcionais, incluindo emocionais e comportamentais, baixa autoestima e habilidades esportivas limitadas. Outros impactos negativos da DF, citados nos estudos abordados neste artigo foram: crises álgicas (GOMES MV, et al., 2019; FOSTER N e ELLIS M, 2018; ADZIKA VA, et al., 2017; UMEH NI, et al., 2017; DERLEGA VJ, et al., 2014; TAYLOR LEV, et al., 2013; COTTON S, et al., 2012; BEDIAKO SM, et al., 2011; COOPER-EFFA M, et al., 2001); medo da morte, (GOMES MV, et al., 2019); receio da dependência de opioides ( YOON SL e BLACK S, 2006), medo da invalidez e de outros impactos físicos, psicológicos e sociais (PEREIRA SAS, et al., 2008), além de depressão e ansiedade (COTTON S, et al., 2012). Assim, há comprometimento da QV em adultos com DF que estão com dor grave, ansiosos, depressivos, hospitalizados e recebendo transfusões de sangue (ADZIKA VA, et al., 2017).

$\mathrm{O}$ uso da E/R pode trazer benefícios ao paciente com DF aliviando a ansiedade, sintomas depressivos, desamparo e pode promover uma melhora na saúde mental, com retomada da esperança e possibilidade de realizar novos planos (COOPER-EFFA M, et al., 2001; DERLEGA VJ, et al., 2014; GOMES MV, et al., 2019). Dentre os benefícios da utilização da E/R no enfrentamento da DF, o alívio da dor, incluindo a dor crônica na DF, é um dos mais relevantes. (GOMES MV, et al., 2019; UMEH NI, et al., 2017; CLAYTON-JONES D, et al., 2016; CLAYTON-JONES D e HAGLUND K, 2015; TAYLOR LEV, et al., 2013; COTTON S, et al., 2012; BEDIAKO SM, et al., 2011; ADEGBOLA M, 2011; HARRISON MO, et al., 2005; COOPER-EFFA M, et al., 2001).

Umeh NI, et al. (2017) perceberam que 50\% dos pacientes com úlcera de perna relataram que a religião serve como um meio de superar a carga psicossocial da DF e suas úlceras nas pernas e que, para muitos, a religião era uma estratégia de enfrentamento e conforto. $O$ consenso parece indicar que a religião confere benefícios psicológicos e físicos. Um estudo canadense evidenciou que portadores de dores crônicas e fadiga possuem melhor perfil psicológico quando são religiosos (BEDIAKO SM, et al., 2011).

A espiritualidade, embora considerada um elemento importante da vida, tem apresentado pouca ênfase na prática médica. Para Gomes MV, et al. (2019), ignorar esse quesito nos pacientes com DF significa negligenciar a assistência integral ao paciente, muito embora essa abordagem seja desafiadora ao profissional da saúde. Outros estudos apontam a importância de os profissionais de saúde abordarem sobre o enfrentamento religioso de seus pacientes, bem como os aspectos espirituais, fazendo com que os médicos, em especial, conheçam melhor essa perspectiva (TAYLOR LEV, et al., 2013; COTTON S, et al., 2012; YOON SL e BLACK S, 2006).

No estudo de Taylor LEV, et al. (2013), 95\% dos pacientes desejam que seus profissionais de saúde abordem aspectos espirituais. Adegbola M, (2011) diz que a espiritualidade do paciente deve ser vista de maneira conjunta na avaliação e intervenção de saúde, sendo incorporada como um modelo integralista na assistência dos cuidados de saúde. Para Derlega VJ, et al. (2014) pacientes que dialogam sobre seus sentimentos com os prestadores de assistência médica está positivamente relacionado à vontade de procurar assistência médica num futuro episódio de dor.

Royal CD, et al. (2000) avaliaram o impacto do ambiente familiar com criança com DF, morbidade e status socioeconômico nas estratégias de enfrentamento da doença e perceberam que pacientes em famílias mais religiosas utilizavam a religião como forma de enfrentamento. Para Cotton S, et al. (2012), muitos fatores contribuem para o modo como a criança lida com uma doença crônica, levando em consideração fatores da doença em si, fatores pessoais, familiares e sociais. Nesse contexto, filhos de pais adeptos às MACs, são 
mais propensos a utilizar dessas ferramentas no enfrentamento da doença (COTTON S, et al., 2009; YOON SL e BLACK S, 2006). Entretanto, se crianças com DF utilizam enfrentamento religioso, é necessário que seus médicos conheçam esse cenário, a fim de integrá-lo às discussões sobre gerenciamento da doença e da dor. Neste estudo, a maioria das crianças disseram que suas famílias oravam por elas e que a oração em família foi eficaz para ajudá-las a se sentirem melhor.

Já no estudo de Clayton-Jones D, et al. (2019), com adolescentes de 15 a 19 anos com DF, concluiu-se que a espiritualidade pode ser particularmente significativa para adolescentes que vivem com DF em comparação com outras faixas etárias ou que não vivem com uma doença crônica. Soma-se a esse estudo o de Clayton-Jones D, et al. (2016) que realizou uma pesquisa com perfil populacional semelhante. Parte dos entrevistados relatou sentir conforto e obter visão diferente sobre suas experiências em seu relacionamento com Deus diante dos desafios para lidar com a DF.

Para Toni-Uebari TK e Inusa BPD (2009) o envolvimento de líderes religiosos e organizações religiosas em intervenções de saúde melhora o nível de aceitação, participação e resultados positivos para a saúde dentro das comunidades de fé. Cotton S, et al. (2009) e Clayton-Jones D, et al. (2016) corroboram com a importância da presença de um líder religioso para alguns pacientes.

\section{CONSIDERAÇÕES FINAIS}

Diante da cronicidade e complexidade de acometimentos que os indivíduos com DF experimentam, o uso de MACs se faz presente para um melhor enfrentamento da doença, porém, não deve substituir nenhuma conduta terapêutica convencional. Dentre as MACs utilizadas, a E/R se destaca na frequência e com resultados significativos na melhora da QV do paciente. Neste contexto, o profissional de saúde precisa atentar-se à vivência do paciente, respeitar suas crenças, inclusive quando inexistirem, e despir-se de suas próprias convicções, para que através da abordagem da $E / R$ se consiga oferecer uma atenção integral à saúde do paciente. Por fim, a literatura carece de estudos com número maior de pacientes para investigar de maneira direta e mais objetiva o impacto da E/R no processo saúde-doença do paciente com DF.

\section{AGRADECIMENTOS E FINANCIAMENTO}

À Liga Acadêmica de Hematologia (Hemoliga) da cidade de Juiz de Fora pela oportunidade de desenvolver o presente estudo, à Fundação Hemominas e à FAPEMIG (Fundação de Amparo à Pesquisa do Estado de Minas Gerais) pelo apoio financeiro.

\section{REFERÊNCIAS}

1. ADEGBOLA M. Spirituality, Self-Efficacy, and Quality of Life among Adults with Sickle Cell Disease. South Online J Nurs Res, 2011; 11(1): 1-16.

2. ADZIKA VA, et al. Socio-demographic characteristics and psychosocial consequences of sickle cell disease: the case of patients in a public hospital in Ghana. Journal of Health, Population and Nutrition, 2017; 36:4.

3. AHMED S, et al. The influence of faith and religion and the role of religious and community leaders in prenatal decisions for sickle cell disorders and thalassaemia major. Prenat Diagn, 2006; 26: 801-809

4. BAVERSTOCK A, FINLAY F. Faith healing in paediatrics: what do we know about its relevance to clinical practice? Child: care, health and development, 2011; DOI:10.1111/j.1365-2214.2011.01284.x

5. BEDIAKO SM, et al. Religious coping and hospital admissions among adults with sickle cell disease. J Behav Med, 2011; 34(2): 120-127.

6. CHO LH, et al. Motivations and Decision-Making of Adult Sickle Cell Patients in High-Risk Clinical Research. Biology of Blood and Marrow Transplantation, 2020; 00 (2020): 1-8.

7. CLAYTON-JONES D, et al. Spirituality and Religiosity in Adolecents Living With Sickle Cell Disease. Western Journal of Nursing Research, 2016; 1-18.

8. CLAYTON-JONES D, HAGLUND K. The Role of Spirituality and Religiosity in Persons Living With Sickle Cell Disease. Journal of Holistic Nursing, 2015; 20 (10).

9. CLAYTON-JONES D, et al. Use of the Spiritual Development Framework in Conducting Spirituality and Health Research with Adolescents. Journal of Religion and Health, 2019.

10. COOPER-EFFA M, et al. Role of Spirituality in Patients with Sickle Cell Disease. J Am Board Fam Pract, $2001 ; 14$ (2): $116-22$.

11. COTTON S, et al. Religious/Spiritual Coping in Adolescents With Sicke Cell Disease. J Pediatr Hematol Oncol, 2009; 31(5): 313-318. 
12. COTTON S, et al. Religious Coping and the Use of Prayer in Children With Sickle Cell Disease. Pediatr Blood Cancer, 2012; 58:244-249.

13. CRONIN RM, et al. Modifying factors of the health belief model associated with missed clinic appointments among individuals with sockle cell disease. Hematology, 2018; DOI: 10.1080/10245332.2018.1457200

14. DERLEGA VJ, et al. How Patients' Self-Disclosure about Sickle Cell Pain Episodes to Significant Others Relates to Living with Sickle Cell Disease. Pain Medicine, 2014; 15: 1496-1507.

15. DENNIS-ANTIWI JA, et al. Relation Between Religious Perspectives and Views on Sickle Cell Disease Research and Associated Public Health Interventions in Ghana. Journal of Genetic Counseling, 2018.

16. FOSTER N, ELLIS M. Sickle cell anaemia and the experiences of young people living with the condition. Nursing Children and Young People, 2018.

17. GOMES MV, et al. "À espera de um milagre": espiritualidade/religiosidade no enfrentamento da doença falciforme. Revista Brasileira de Enfermagem, 2019; 72(6): 1632-9.

18. GOMES NS, et al. Espiritualidade, Religiosidade e Religião: Reflexão de Conceitos em Artigos Psicológicos. Revista de Psicologia da IMED, 2014; 6(2):107-112.

19. HARRISON MO, et al. Religiosity and Sickle Cell Pain. J Nerv Ment Dis, 2005; 193(4): 250-257.

20. JONASSAINT CR, et al. Clinical and Sociodemographic Factors Predict Coping Styles Among Adults With Sickle Cell Disease. Journal of the National Medical Association, 2010; 102(11): 1045-1049.

21. MACHARIA WM, et al. Knowledge, attitudes and beliefs of primary caretakers towards sickle cell anaemia in children. East Afr Med J., 1997; 74(7): 416-419.

22. MAJUMDAR S, et al. The use and effectiveness of complementary and alternative medicine for pain in sickle cell anemia. Complementary Therapies in Clinical Practice, 2013. 19: 184-187.

23. MARSH VM, et al. 'All her children are born that way': gendered experiences of stigma in families affected by sicke cell disorder in rural Kenya. Ethnicity \& Health, 2011; 16(4-5): 343-359.

24. PEREIRA SAS, et al. Doença falciforme e qualidade de vida: um estudo da percepção subjetiva dos pacientes da Fundação Hemominas, Minas Gerais, Brasil. Rev. Bras. Hematol. Hemoter, 2008; 30(5): 411-416

25. ROYAL CD, et al. Coping strategies in families of children with sickle cell disease. Ethn Dis. 2000; 10(2) :237-47.

26. TAYLOR LEV, et al. A Biopsychosocial-Spiritual Model of Chronic Pain in Adults with Sickle Cell Disease. Pain Management Nursing, 2013; 14 ( 4) : 287-301.

27. TONI-UEBARI TK, INUSA BPD. The role of religious leaders and faith organisations in haemoglobinopathies: a review. BMC Blood Disorders, 2009; 9:6.

28. UMEH NI, et al. The psychosocial impact of leg ulcers in patients with sicke cell disease: I don't want them to know my little secret. PLoS ONE, 2017; 12(10):e0186270.

29. YOON SL, BLACK S. Comprehensive, Integrative Management of Pain for Patients with Sicke-Cell Disease. The Journal of alternative and complementary medicine, 2006; 12(10): 995-1001. 